\title{
Building an Electronic Book on the Internet: "CSEP - an Interdisciplinary Syllabus for Teaching Computational Science at the Graduate Level."
}

\author{
C. Edward Oliver \\ Michael R. Strayer \\ Oak Ridge National Laboratory* \\ P. O. Box 2008 \\ Oak Ridge, TN 37831-6259 \\ Verena M. Umar \\ Vanderbilt University \\ 105 Computer Center \\ Nashville, TN 37240
}

To be presented at the Frontiers in Education Conference, San Jose, CA, November 2 -6, 1994; to be published in the Proceedings.

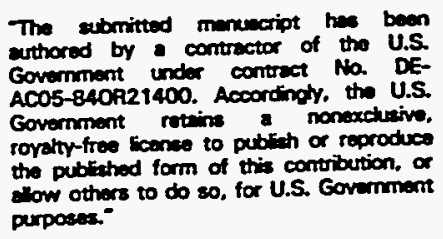

*Managed by Martin Marietta Energy Systems, Inc. under contract DE-AC05-840R21400 with the U.S. Department of Energy

\section{DISCLAIMER}

This report was prepared as an account of work sponsored by an agency of the United States Government. Neither the United States Government nor any agency thereof, nor any of their employees, makes any warranty, express or implied, or assumes any legal liability or responsibility for the accuracy, completeness, or usefulness of any information, apparatus, product, or process disclosed, or represents that its use would not infringe privately owned rights. Reference herein to any specific commercial product, process, or service by trade name, trademark, manufacturer, or otherwise does not necessarily constitute or imply its endorsement, recommendation, or favoring by the United States Government or any agency thereof. The views and opinions of authors expressed herein do not necessarily state or reflect those of the United States Government or any agency thereof. 


\section{DISCLAIMER}

Portions of this document may be illegible in electronic image products. Images are produced from the best available original document. 


\section{Building an Electronic Book on the Internet: "CSEP - an Interdisciplinary Syllabus for Teaching Computational Science at the Graduate Level."}

\author{
C.Edward Oliver, Michael R.Strayer \\ Oak Ridge National Laboratory*
}

\author{
Verena M.Umar \\ Vanderbilt University
}

\section{INTRODUCTION}

The Computational Science Education Project was initiated in September 1991, by the Department of Energy to develop a syllabus for teaching interdisciplinary computational science. CSEP has two major acitivites. The writing and maintenance of an electronic book (e-book) and educational outreach to the computational science communities through presentations at professional society meetings, journal articles, and by training educators. The interdisciplinary nature of the project is intended to contribute to national technological competitiveness by producing a body of graduates with the necessary skills to operate effectively in high performance computing environments $[1,2]$.

The e-book introduces students from diverse disciplines, including Computer Science, Mathematics, and the applied sciences, to high performance computing. The initial version of these materials was completed and made available to the educational community in November of 1993 [3].

The educational outreach guides and supports instructors in developing computational science courses and curricula at their institutions. The CSEP ebook provides valuable teaching material around which educators have built. The outreach not only introduces new educators to CSEP, but also establishes a synergistic relationship between CSEP authors, reviewers and users.

\section{COMPUTATYONAL SCIENCE}

Computational Science is an emerging and rapidly changing discipline with a number of open issues. As discussed by Ken Wilson in the late 1980's [4] the computational science community is still in the process of establishing itself and laying down foundations. It is clear that the thrust of the Grand Challenges and developments in computer technology [1] have stimulated the recent growth. The development and communication of algorithms is probably the most demanding intellectual challenge of the field, hampered in part by the lack of a suitable language to disseminate new ideas and developments to such a large, diverse community.

\section{ORGANIZATION}

To date, 35 authors and reviewers have contributed and revised material. They represent a collaboration between universities, research laboratories, and industry, and work in the disciplines of oceanography, aerospace engineering, biology, chemistry, chemical engineering, computer science, earth sciences, mechanical engineering, nuclear engineering, numerical mathematics and physics. CSEP activities are directed by a steering committee and are implemented with the help of a number of assistants.

\section{TECHNICAL FEATURES}

Users of CSEP materials access hypermedia materials over the World Wide Web. The URL address at which to find the principal copy of the ebook is

$$
\text { http://csepl.phy.ornl.gov/csep.html }
$$

which points to a SGI Challenge, server on the ESNET. Since the documents are in html (hypertext marker language), any html browser can display them. Html browsers, for example NCSA's mosaic, are easy to learn and available for a variety of platforms including Unix workstations, Macintosh and Personal Computers.

Furthermore, the hypermedia format permits for inclusion of animations, color images, interactive shell scripts to interact with graphics software and other programs on their own workstations by clicking buttons in the document. Since onsite availability of the e-book bypasses network delays on the Internet, CSEP offers electronic distribution of all the public domain software and hypermedia materials used in the ebook. 


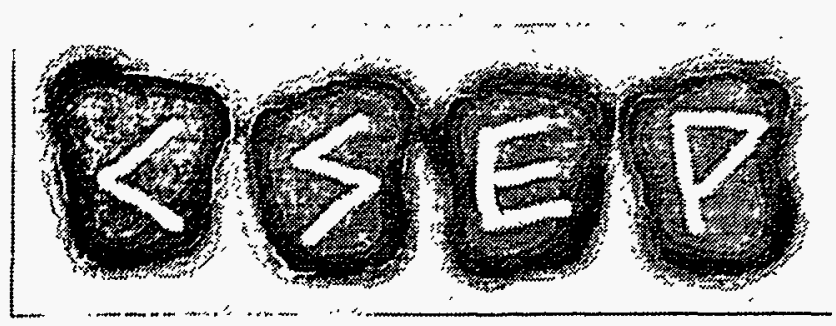

Figure I

Figure 1 shows the CSEP logo as viewed with NCSA's Mosaic on the homepage. The homepage includes information on our activities, a path to the table of contents, instructions for contributors and a feedback and registration form. Throughout the syllabus navigational icons allow the reader to move freely between chapters, figures, references, the table of contents and other information. Some of these icons are shown in figure 2 as they would appear at the top and bottom of each scrollable text window.

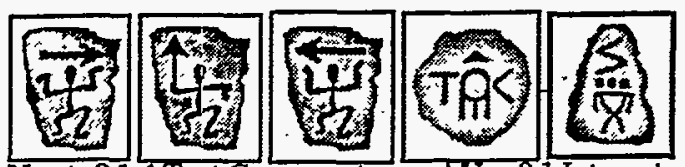

Next: 3.1.4 Text Compression and Up: 3.1 Internet and the Previous: 3.1 .2 Network News

Figure 2

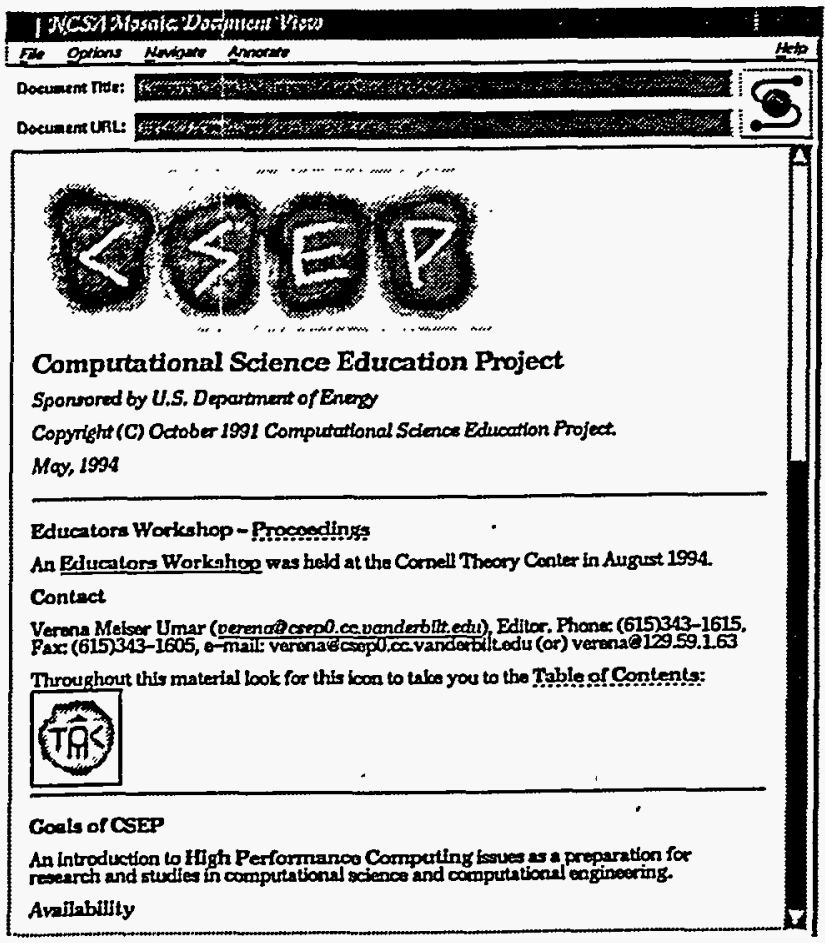

Figure 3
Figure 3 shows the top portion of the CSEP homepage. This window leads the reader to the table of contents of the chapters, to workshop announcements and proceedings, to a list of the chapters under preparation, to authoring guidelines, to reader suggestions, and to the feedback and registration form.

\section{SYLLABUS}

CSEP materials are laid out in three parts. The first is an introduction to high performance computing. Issues such as "What is Computational Science?" and the historical perspectives not only of hardware and software but also of infrastructure and initiatives on government level are addressed. Modern programming languages, in particular Fortran90, computer architectures and networks are introduced. A chapter on scientific visualization discusses the benefits of using visualization for effective data entry, for debugging of codes and for performance analysis, in addition to its more familiar use of interpretation and presentation of results. Tutorials for some of the numerous public domain graphics and visualization packages available on the Internet and used throughout CSEP chapters are appended. Some of the software used is $\mathrm{xv}$, xmgr, xpaint, Khoros, ImageMagick, Utah Raster Toolkit, Generic Mapping Tool $[5,6]$, Plotmtv, and NCSA's Image, Dataslice, Imagetools and Mosaic.

The second part discusses modern computational methods. The current version of CSEP materials includes discussions of methods in linear algebra, mathematical optimization, ordinary and partial differential equations, monte carlo methods, as well as random number generation.

The third part is a collection of case studies presenting one or more worked examples of the computational methods discussed in part two. The current version includes such studies in ocean modeling, bioelectric field problems arising in the health sciences, photon transport between surfaces, seismic modeling and earth imaging, and chaos from nonlinear maps. Case studies are intended for a general audience that is not assumed to be familiar with the underlying scientific background of the applications presented. These chapters, which can easily take up several weeks of lecture time, contain working codes, primarily in Fortran 77, but also in $\mathrm{C}, \mathrm{C}++$ and Fortran 90 , and in many cases examples of visualization of the data resulting from the execution of these codes. Again, numerous examples and exercises give the students opportunities to test their understanding of a chapter as they work through it. 
The following figure is an example of a visualization a reader can generate after following the instructions and suggestions in the quickstart on plotmtv, a public domain software package, found in the chapter on Scientific Visualization. The quickstart guides readers from the retrieval of the software using ftp, through all the steps to work examples, exercises, and generate visualizations discussed. Figure 4 shows the graph resulting from a superposition of a vector field and a $2-d$ contour graph for which the reader can generate data from provided Fortran codes and given plotmty syntax. Figure 5 is another sample figure, which is taken from the case study on Ocean Models. It shows one frame of an animation that students are guided to generate using Generic Mapping Tools, a public domain mapping tool popular in the area of oceanography.

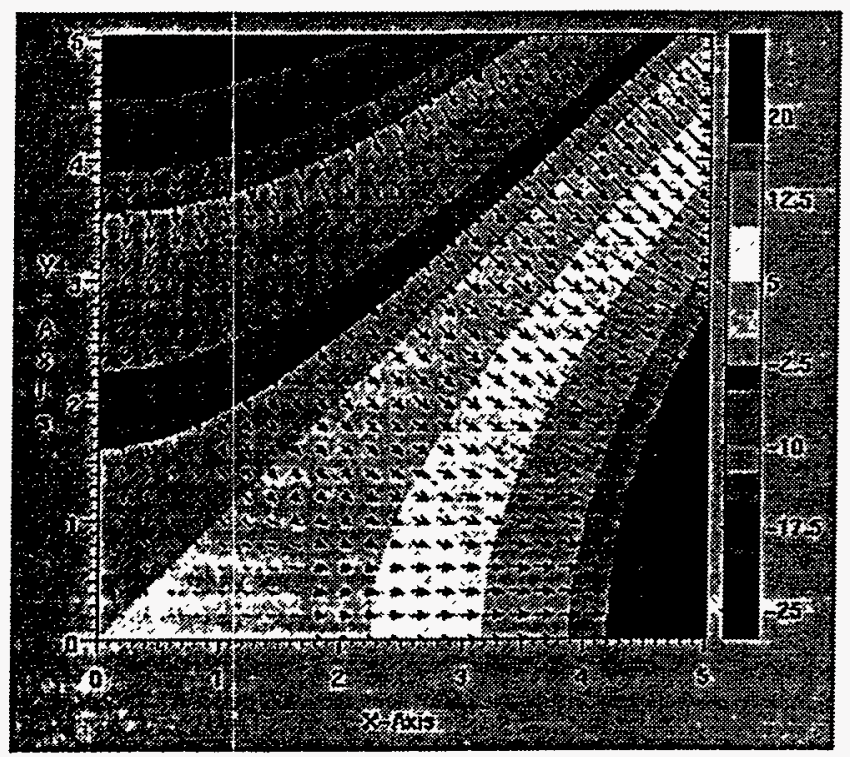

Figure 4

\section{FUTURE DEVELOPMENTS OF THE SYLLABUS}

A set of computational projects is planned. These are short projects that students with little or no background in a discipline can expect to complete in a few weeks time. Such projects can either illustrate an algorithm or a high performance computing technique, and they are not tied to an application in a particular discipline.

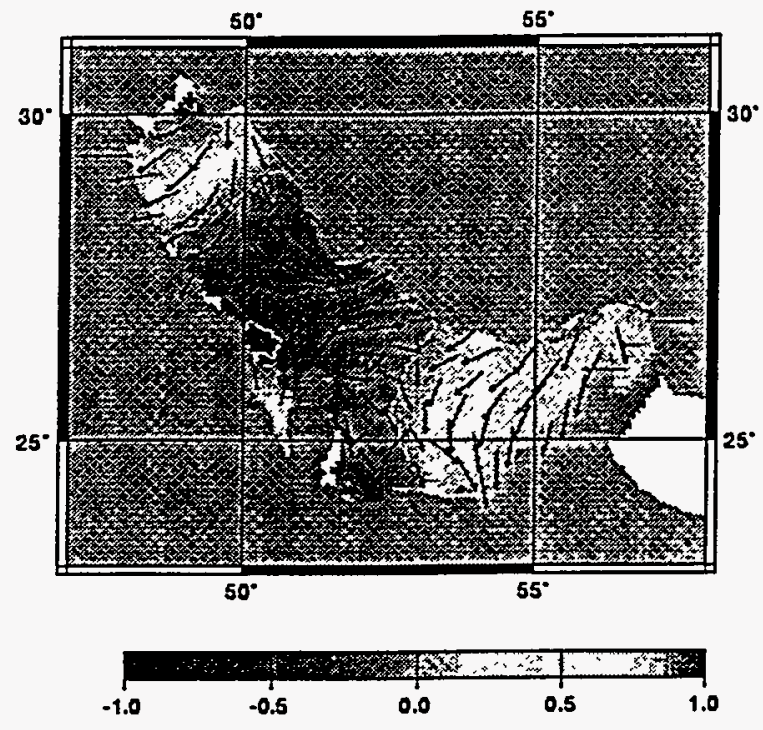

Figure 5 - Persian Gulf Sea Surface Height in Meters Velocities are on a $\log 10$ scale: $1 \mathrm{~cm} / \mathrm{s}=0$

\section{REFERENCES}

[1] High Performance Computing and Information: Toward a National Information Infrastructure. OSTP 1994.

[2] The Computational Science Education Project (CSEP). Proceedings, IEEE Frontiers in Education Conference, 1993.

[3] Proceedings of Supercomputing '93.

[4] Ken Wilson, "Basic Issues for Computational Science" 1986, Trieste, 1986, Unpublished.

[5] - P. Wessel and W.H.F. Smith, Free Software helps map and display data, EOS Trans. AGU, 72, 441, 445-446, 1991. [6] - W.H.F. Smith and P. Wessel, Gridding with continuous curvature splines in tension, Geophysics, 55, 293-305, 1990.

\section{FIGURE CAPTIONS}

[1] The CSEP logo.

[2] Navigational Icons . In order from left to right they take the reader to the next section or subsection, the parent section, the previous section or subsection, the table of contents of the e-book and to the search tool interface. [3] Top portion of the CSEP homepage at URL: http:// csep1.phy.ornl.gov/csep.html 
[4] Overlay of the color raster map of $z=x^{2}-y^{2}$, where $\mathrm{x}$ and $y$ range over a rectangular mesh over the region $0<x$, $y<5$ and the vector field that is the gradient of the above function. The plot was generated using the public domain software package plotmtv.

[5] One frame of an animation that is part of the tidal model exercise in the case study on Ocean Models. The figure shows a color map of sea surface height and superimposed velocity vectors that indicate the magnitude and direction of average tidal currents.

\section{t****}

\section{Edward Oliver}

Dr. C. Edward Oliver received his Ph.D. in Mathematics in 1969 from the University of Alabama. He is currently the Associate Director of Oak Ridge National Laboratory for Computing, Networking, Informatics, and Education.

\section{Michael R. Strayer}

Dr. Michael R. Strayer received his Ph.D. in Physics from M.I.T. He is presently the Section Head of Theoretical and Computational Physics at Oak Ridge National Laboratory.

\section{Verena M. Umar}

Verena M. Umar received an M.S. in Applied Mathematics from Claremont Graduate School and an M.S. in Computer Science from Vanderbilt University. She is currently Editorial an d Technical Assistant to the Computational Science Education Project and part of the Research Support group at the Vanderbilt University Computer Center.

*Managed by Martin Marietta Energy Systems, Inc. under contract DE-AC05-84OR21400 with the U.S. Department of Energy. 